\title{
Correction to: Below-ground nitrogen transfer from oak seedlings facilitates Molinia growth: ${ }^{15} \mathrm{~N}$ pulse-chase labelling
}

\author{
Marine Fernandez • Philippe Malagoli • Antoine \\ Vernay • Thierry Améglio • Philippe Balandier
}

Published online: 30 April 2020

(C) Springer Nature Switzerland AG 2020

\section{Correction to: Plant and Soil. \\ https://doi.org/10.1007/s11104-020 \\ $-04473-9$}

In the published version of this paper, the titles for figs. 3 and 4 should be presented as below:

Fig. $3{ }^{15} \mathrm{~N}$ allocation (expressed as $\%$ of total ${ }^{15} \mathrm{~N}$ measured in all compartments) among shoots, roots and soil in donor oak and receiver Molinia. Species

The online version of the original article can be found at https://doi.org/10.1007/s11104-020-04473-9

M. Fernandez $\cdot$ P. Malagoli $(\bowtie) \cdot$ T. Améglio Université Clermont Auvergne, INRAE, PIAF, F-63000 Clermont-Ferrand, France

e-mail: philippe.malagoli@uca.fr

M. Fernandez

e-mail: marine.fernandez@uca.fr

T. Améglio

e-mail: thierry.ameglio@inrae.fr
A. Vernay Sweden
e-mail: antoine.vernay@slu.se
P. Balandier
INRAE, UR EFNO, Domaine des Barres,
F-45290 Nogent-sur-Vernisson, France
e-mail: philippe.balandier@inrae.fr

Department of Forest Ecology and Management, Swedish, University of Agricultural Sciences (SLU), SE-901 83 Umea, were sole-grown (a, b, c and d) or mixed-grown (e, f, $\mathrm{g}$ and $\mathrm{h}$ ), for each season: summer (a and e), autum (b and $\mathrm{f}$ ), winter (c and $\mathrm{g}$ ) and spring ( $\mathrm{d}$ and $\mathrm{h})$. Values are reported as means $\pm \operatorname{SE}(n=4)$

Fig. $4{ }^{15} \mathrm{~N}$ allocation (expressed as $\%$ of total ${ }^{15} \mathrm{~N}$ measured in all compartments) among shoots, roots and soil in donor oak and receiver oak. Species were sole-grown (a, b, c and d) or mixed-grown (e, f, g and h), for each season: summer ( $a$ and $e$ ), autum ( $b$ and $f$ ), winter ( $\mathrm{c}$ and $\mathrm{g}$ ) and spring ( $\mathrm{d}$ and $\mathrm{h}$ ). Values are reported as means $\pm \operatorname{SE}(n=4)$

Publisher's note Springer Nature remains neutral with regard to jurisdictional claims in published maps and institutional affiliations. 